\title{
Pesquisa com crianças na Educação Física: questões teóricas e desafios metodológicos*
}

\author{
Eliane Gomes-da-Silva ${ }^{* *}$ \\ Márcia Buss-Simão ${ }^{* * *}$
}

\section{Resumo:}

O presente ensaio busca ampliar subsídios que permitam uma compreensão do ponto de vista das crianças na dimensão da pesquisa em Educação Física Infantil. Trata-se de uma reflexão teórica, na qual a revisão da literatura permitiu delimitar os parâmetros da abordagem do tema e propor sua problematização. A conclusão aponta para necessidade de se adotar, nas pesquisas com crianças, uma abordagem multidisciplinar como aporte metodológico que possibilite, de fato, perceber e incluí-las como partícipes da e na produção de conhecimentos, especialmente aqueles que as afetam diretamente e que podem perspectivar novas formas de intervenção educativa.

Palavras-chave: pesquisa, infância, educação física, educação infantil.

\section{Introdução}

O encontro multidisciplinar da Pedagogia e da Educação Física com a Sociologia, a Antropologia, a História e a Filosofia permitiu grandes avanços nesses dois campos investigativos, especialmente no que se refere à categoria infância. Uma parte considerável desses estudos propõe a superação das concepções de criança como um vir a ser, como tabula rasa ou como adulto em miniatura. As críticas têm se estendido também à idéia de uma infância universal e única, graças, sobretudo, ao trabalho de Ariès (1981) que muito contribuiu para iluminar novas formas de conceber as infâncias e as crianças, embora, em muitos aspectos tenha recebido críticas pertinentes,

\footnotetext{
* Esse artigo, originalmente, foi publicado na revista Inter-Ação - Revista da Faculdade de Educação da UFG - no Volume 33 do segundo semestre de 2008 em versão impressa e online no site: http://www.revistas.ufg.br/index.php/interacao/issue/archive.

** Doutoranda do Programa de Pós-Graduação em Educação da Universidade de São Paulo - FEUSP.Docente das Faculdades Origenes Lessa -FACOL E-mail: nani.gomes@terra.com.br

*** Doutoranda do Programa de Pós-Graduação em Educação da Universidade Federal de Santa Catarina - PPGE/UFSC. Pesquisadora do Núcleo de Estudos e Pesquisas da Educação na Pequena Infância -NUPEIN/CED/UFSC. E-mail: marcia@ced.ufsc.br
} 
especialmente por descrever uma visão histórica linear e por apresentar limites metodológicos de pesquisa, bastante estreitos.

Entre os muitos resultados destes debates já é possível depreender que, em sendo diversas as configurações sociais, culturais, políticas e econômicas constituídas em diferentes momentos históricos e espaços geográficos diversos, diversas serão também as infâncias e as crianças que as constituem, o que significa ter que encarar tais categorias como plurais.

A contribuição de todos os campos teóricos acima mencionados para uma compreensão mais abrangente da complexidade que define a especificidade da infância é inegável. Esta constatação exige que envidemos esforços cada vez maiores na busca do diálogo e do debate entre diferentes campos teóricos de forma a favorecer a superação das dificuldades que enfrentamos com relação às crianças, às infâncias e às pesquisas no processo educativo.

Colocado o desafio, resolvemos iniciar nossas indagações pelo campo da Sociologia da Infância e pelas questões por ele suscitadas - ou ressuscitadas, já que várias das indagações já estavam, em alguma medida, presentes em outros campos, como na Filosofia, por exemplo.

\section{Refletindo com a Sociologia da infância}

O nosso interesse inicial pela Sociologia da Infância deve-se ao fato desse campo sociológico, de forma ampla, reconhecer e assumir a necessidade de se focalizar, pontualmente, a categoria da infância, ao invés de contentar-se com a atitude do olhar periférico que a Sociologia lançava a essa categoria. Segundo Qvortrup (1999), até pouco tempo, as infâncias e as crianças só eram sociologicamente compreendidas a partir do foco teórico-metodológico centralizado na Sociologia da Família, da Educação, da Justiça, etc.

No argumento de Sirota (2001), foi um movimento na própria Sociologia que despertou interesses em reencontrar e assumir as crianças como atores no processo de socialização. Vale aqui já anunciar o alerta dessa autora ao fato de serem principalmente os campos da Fenomenologia, da Sociologia Interacionista e das abordagens Construtivistas que, passam a fornecer importantes suportes teóricos a essa abordagem. Assim, anunciado fica a importância de adotarmos, no âmbito da pesquisa com crianças, uma postura teórico-metodológica multidisciplinar.

No âmbito da Educação Física, Silva (2003) já denunciou ter sido apenas nos anos 1990 que, timidamente, iniciou-se um debate mais crítico sobre a infância no Brasil, tendo em conta questões de classe social, gênero, raça / etnia, geração e cultura. Para esse autor, mesmo quando lançamos o olhar à produção científica no campo das Ciências Sociais e Humanas, o que se segue é que os temas relativos à infância ainda não são tratados de modo sistemático e aprofundado. Silva (2003) acredita 
que ainda faltam abordagens multidisciplinares, que permitam tratar, articular e privilegiar temas transversais como educação, trabalho, lazer, corpo e outros na Educação Física.

O que a Sociologia da Infância prioriza é o entendimento da criança como ator social capaz de atuar como partícipe na produção do conhecimento e a infância como entidade ou instituição construída do ponto de vista social. Sarmento e Pinto (1997), em contraposição às perspectivas predominantemente biologicistas, apresentam a infância como uma categoria social, logo, uma estrutura, já que é uma permanência na estrutura social e todas as crianças, inevitavelmente, passam por ela. Entretanto, esta não é uma estrutura estática, mas resulta da concepção de geração, ou seja, um momento próprio dos seres humanos, um tempo vivido na magia - corpórea / perceptivo e sensível - de uma especificidade geracional.

Nessa mesma direção, Kuhlmann Jr. (2001) defende a infância como uma condição das crianças, ao mesmo tempo em que não existe um só tipo de infância, mas várias infâncias. Assim, cada criança passa pela categoria da infância a seu modo, com suas condições concretas de vida, com suas inter-relações próprias. Noutras palavras, cada criança tem a sua própria infância.

A compreensão dos conceitos de infâncias e crianças - no plural -, leva em conta a complexidade que as constituem, ou seja, considera as suas diferenças individuais (singulares), culturais, étnicas / raciais, geracionais, de gênero e de religião, além de indicar que, é possível, que ainda não conhecemos, verdadeiramente, as crianças. Nesta perspectiva, às crianças é concedido também o estatuto de sujeitos de direitos, sobretudo, naquilo que as afetam diretamente. Do ponto de vista da infância como categoria social, é preciso levar em conta que ela se distingue (mas não se isola) de outros grupos e, dessa maneira, as crianças são atores sociais com direitos à participação ativa na sociedade (SARMENTO E PINTO, 1997).

Contudo, não obstante esses apontamentos, o que ainda percebemos é que - embora sob égide de novas propostas, novas perspectivas e avanços metodológicos - o que ainda prevalece, ou subjaz, os discursos acadêmicos, são condutas que em geral privilegiam olhares adultocêntricos ${ }^{2}$ acerca da categoria da infância, e contribuem em ratificar a idéia de que ser criança implica pressupostos condicionados em dicotomias.

\section{Fundamentos básicos da Sociologia da Infância}

\footnotetext{
${ }^{2}$ De acordo com Gobbi (1997, p. 26) "[...] o termo adultocêntrico aproxima-se aqui de outro termo bastante utilizado na Antropologia, o etnocentrismo. Aqui, a visão de mundo segundo a qual o grupo ao qual pertencemos é tomado como centro de tudo e os outros são olhados segundo nossos valores, criando-se um modelo que serve de parâmetro para qualquer comparação. Nesse caso o modelo é o adulto e tudo passa a ser visto e sentido segundo a ótica do adulto, ele é o centro".
} 
Segundo Gaitán (2006), a Sociologia da Infância não se define numa abordagem única, ao contrário, agrega em seu interior, diferentes e conflitantes perspectivas. Entretanto, destaca a autora, o elo que une essas perspectivas é, justamente, o interesse em entender como se estabelecem as relações entre os sujeitos sociais, sejam elas entre os adultos e as crianças ou entre as crianças mesmas. Desta forma, a não unanimidade no interior desse campo, também suscita inúmeros questionamentos e desajustes que são necessários se pretendemos estudar as crianças a partir delas mesmas (de suas próprias necessidades e desejos) e não apenas subordinadas a instituições como escola, família, justiça, etc.

A Sociologia da Infância, compreendida como perspectiva crítica, vem se opor à Sociologia Moderna, cujo discurso é insuficiente para lidar adequadamente com a instabilidade e a desordem do mundo atual, pois, ora restringe a criança à demasiada passividade, ora a deixa como elemento permanente da estrutura social. Para Prout (2004), a Sociologia moderna fundamenta-se basicamente em dicotomias (ação / estrutura, natureza/cultura, ser / devir). A proliferação de dicotomias marca, desse modo, a Sociologia Moderna, as quais, por sua vez, dividem a realidade social em tópicos distintos: estrutura x ação, local x global, identidade x diferença, continuidade x mudanças, etc.

O ponto de partida dessa análise encontra-se na reflexão de que, essas dicotomias, por cuja construção a modernidade lutou, já não cabem mais para perceber os fenômenos da contemporaneidade, sobretudo o da criança, que, por não operar/viver com base numa lógica formal de racionalidade, torna-se inapreensível na sua plenitude.

Para Prout (2004, p. 8), um dos motivos que levou a sociologia moderna a negligenciar a infância foi justamente o fato de ela parecer desafiar a dicotomia natureza x cultura: “ $\mathrm{O}$ caráter híbrido da infância em parte natural, em parte social, parece claramente não estar à vontade com a mentalidade moderna e a sua preocupação em dicotomizar". Vale apontar que, é justamente esse debate epistemológico, que torna possível perceber a tensão entre a lógica própria da criança e a soberana sabedoria do adulto, sendo este, comumente, o único propositor no que se refere à educação e à pesquisa.

De fato, freqüentemente, ao se tratar de crianças e instituições escolares na esfera da pesquisa, de um lado se afirma que as crianças / alunos são os sujeitos fundamentais do processo; de outro, o fascínio por uma cientificidade formal nos moldes da racionalidade, instaura uma contradição, ao deixar de lado os atores principais: as crianças/alunos.

Mas, como permitir plena participação das crianças no processo de produção de conhecimento, diante do fato apontado por Iturra (2002, p. 151) de que "[...] o que a criança não tem é palavras para explicitar o que entende à sua medida, em pequeno" ? Esta condição não intensifica a nossa responsabilidade no âmbito da Educação Física diante de sua especificidade pedagógica? Será 
que estamos abertos e preparados para 'ler', 'interpretar' e incluir as crianças nas pesquisas para além da sua capacidade de verbalização?

Nessa perspectiva, James, Jenks e Prout (2000, p. 209), ao pensarem a dimensão corporal das crianças - que também a sociologia negou, deixando-a dicotomizada frente a outras dimensões sugerem que a vejamos como uma ação social corporificada, efetuada não apenas por textos, mas por crianças reais, vivas, integradas e, deste modo, corpóreas. Crêem, esses autores, que os discursos sobre a infância, mesmo quando se tratam de pesquisas etnográficas, preocupadas com a recolha da voz das crianças, muitas vezes, não conseguem “[...] perceber a importância da corporificação nos processos por meio dos quais as crianças participam na vida social”.

Na esteira dessas reflexões, entendemos que, no âmbito da Educação Física infantil, a busca pelo modo e espaço de participação efetiva das crianças mediante as suas mais diversas formas de expressão, é doravante a grande tarefa desse campo.

A própria Convenção da Organização das Nações Unidas sobre os Direitos da Criança (ONU, 1989), envolve versões dos direitos de autonomia dos adultos e contemplam o respeito ao direito à participação das crianças em atividades e decisões que as afetam. Assim, o estatuto de sujeitos de direitos, outorgados às crianças, só poderá ser efetivado na medida em que às crianças for possibilitada a participação plena em todos os âmbitos da sociedade, sobretudo naquilo que lhe dizem respeito, como é o caso das instituições educativas.

\section{Aspectos a serem considerados}

Sarmento e Pinto (1997) argumentam que dentre os três $P$ (Proteção, Provisão e Participação), previstos às crianças nas construções das políticas e na organização e gestão das instituições para infância, o que menos progresso tem obtido é o direito à participação. É do argumento desses mesmos autores que a participação não se desenvolve por si mesma, mas há necessidade de uma ação / providência - no nosso caso investigativa - capaz de favorecer o exercício da decisão pelas crianças, ou seja, é preciso que viabilizemos sua participa-AÇÃO. Embutido neste mesmo entendimento está a possibilidade de proporcionarmos às crianças, a sua tão defendida emancipação social.

O nosso dever, então, é desconstruir a idéia de criança como infante, expressão que, conforme (Gimeno Sacristán 2005), vem de infans, que significa o que não fala; não porque não possua capacidade para isso, mas porque a palavra lhe é negada. Só assim será possível conceder, no âmbito da pesquisa, vez e voz às crianças. Como bem aponta Sarmento: 
[...] todas as crianças, desde bebés, têm múltiplas linguagens (gestuais, corporais, plásticas e verbais,) por que se expressam. A infância não é a idade da não-razão: para além da racionalidade técnicoinstrumental, hegemónica na sociedade industrial, outras racionalidades se constróem, designadamente nas interacções entre crianças, com a incorporação de afectos, da fantasia e da vinculação ao real. [...] A infância não vive a idade da não-infância: está ai, presente nas múltiplas dimensões que a vida das crianças (na sua heterogeneidade) continuamente preenche (SARMENTO, 2005, p. 25).

Assim, aos adultos, aos pesquisadores, cabe o compromisso de reaprender a ouvir, a escutar as crianças e dar possibilidade para sua ação participativa, tal como promulga os Direitos da Criança ao concebê-los como sujeitos capazes e plenos. É oportuno aqui citar Roberts $(2005$, p. 258) ao ser categórica em afirmar: "É claro que ouvir e escutar as crianças e agir sobre o que as crianças dizem são três actividades muito diferentes, apesar de serem freqüentemente suprimidas como se não fossem". Para a autora há uma diferença em ouvir e escutar, sendo que escutar envolve, além de ouvir, uma interpretação das vozes das crianças, não sendo estas, apenas figurativas ou ilustrativas. Além da escuta, a autora considera fundamental o agir sobre o que as crianças dizem.

Se aprendermos a ouvir e escutar, podemos perceber que as crianças apontam aos adultos fatos que eles não conseguem mais ouvir nem ver, tamanha sua imersão no congestionamento de códigos já cristalizados da cultura. A criança, por ser relativamente livre desse congestionamento, possui e opera sob outra lógica perceptiva, o que exige que nos libertemos de nossa própria lógica para compreendê-la.

O empenho da participação, objetivando conferir às crianças a concretização do discurso de sujeitos de direitos,

[...] colide com práticas sociais, havendo um hiato acentuado entre a teoria e a prática no que concerne aos direitos de participação das crianças, explicado pela herança sócio-cultural da invisibilidade e "afonia" das crianças, que é muitas vezes perpetuada em função dos próprios interesses dos adultos (TOMÁS e SOARES, 2004, p. 355).

Empenhadas na defesa da possibilidade de participação ativa das crianças na dinâmica social, essas autoras perguntam-se até que ponto a sociedade adulta está preparada para considerar as crianças como possuidoras de direitos, para além da intitulação e aceitando o fato de que as crianças já são, admitamos ou não, sujeitos, cidadãos ativos na sociedade e com ponto de vista, interesses e desejos próprios? 
Vale acrescentar que somos cientes do fato de que a sociedade capitalista não é, de modo algum, alheia ao potencial de consumo das crianças, isto é, às suas demandas, para as quais já se tem voltado especial atenção. Atentos a esse fenômeno, alguns pesquisadores no campo da infância já têm, efetuado esforços em criticar e explicitar a falsa idéia de atenção aos interesses das crianças presentes em tal fenômeno, p. ex. Roberts (2005), Soares e Tomás (2004), Sarmento (2004) e (2005).

Não são, assim, os reais interesses das crianças que são atendidos pela sociedade capitalista. Esta, ao contrário, é que assume, interessadamente, o papel de formadores de consciência ideologicamente falsa, no qual os interesses reais das crianças são desprezados, tornando-se portanto, obscuros, de forma que as caracterizam como reprodutoras de falsos interesses.

Parcial e sumariamente, já podemos afirmar que ouvir as diversas expressões das crianças, permitindo assim a sua plena participação com base nos seus reais, verdadeiros, próprios interesses no sentido de não ser apenas a manifestação de interesses impostos por adultos - são os aspectos mais relevantes que precisamos considerar no processo de pesquisa.

\section{Como sair da lógica adultocentrada nas pesquisas com crianças?}

Boaventura de Souza Santos, respeitado pela sua pronta atitude de tomada de posição frente a condições excludentes de categorias e sujeitos minoritários e marginalizados na sociedade, merece a nossa referência inicial, ao apresentarmos a nossa concepção das possibilidades de superação da lógica adultocentrada prevalecente nas pesquisas com crianças. Tentar ler, interpretar, ou mesmo traduzir as vozes das crianças, é, sem dúvida, nossa maior dificuldade. Por esse motivo, Santos (2008) traz o entendimento de uma ecologia de saberes na qual a lógica da monocultura do saber científico, deve ser confrontada com identificação de outros saberes e critérios que também vigoram nas práticas sociais. Para o autor, o próprio campo da produção do conhecimento pode abrir espaço para o diálogo com outros saberes sociais, de modo a alimentar a produção do conhecimento. A ecologia dos saberes parte do pressuposto de que todas as práticas relacionais entre os seres humanos, e destes com a natureza, implicam mais de uma forma de saber e, portanto, também de ignorância. Assim, a credibilidade desses conhecimentos não-científicos não implica o descrédito do conhecimento científico, mas sua utilização de forma contra-hegemônica.

O princípio de incompletude de todos os saberes é a condição de diálogo e do debate epistemológico entre diferentes formas de conhecimentos: “O que a ecologia dos saberes desafia são as hierarquias universais e abstratas e os poderes que, através delas, têm sido naturalizados pela historia" (SANTOS, 2008, p. 108). No caso específico dos saberes das crianças, o que ocorre, no 
âmbito da produção do conhecimento, é que eles, em geral, são descartados a priori, impedindo o diálogo, sob a justificativa de que não são científicos.

Muitas pesquisas em psicologia, ciências médicas e pedagogia já vêm estudando a própria criança, mas interessaram-se, essencialmente, pelos estágios de desenvolvimento psicológico, pela sua constituição corporal e pelas atividades de ensino-aprendizagem que os pesquisadores e professores julgam mais adequadas para as crianças. Desta forma, as crianças são caracterizadas apenas como sujeitadas e não como sujeitos que possuem e produzem saberes nos processos educativos e investigativos.

Como resultado, então, de cruzamentos multidisciplinares entre Sociologia da Infância, Antropologia da Criança, Fenomenologia, História e outros, a sugestão é que iniciamos por realizar um deslocamento da tradicional forma de fazer pesquisas sobre as crianças para realizar pesquisas com as crianças, dado a importância de se considerar os seus pontos de vistas, interesses e experiências, e assim inclúi-las como partícipes na produção de conhecimentos, especialmente aqueles que as afetam diretamente e que podem indicar novas formas de intervenção educativa.

Para realizar pesquisas com crianças, é necessário, pois, levar em conta também a perspectiva delas, e não somente os interesses e objetivos adultocentrados dos pesquisadores; só assim, efetivamente, as crianças podem deixar de ser meros objetos e passar a ser sujeitos de pesquisa. Somente dessa forma entendemos ser possível conceder legitimidade às crianças outorgando-lhes a conquista de sujeitos de direitos e de se constituírem partícipes na e da vida social e na produção de conhecimentos.

É importante ressaltar que as pesquisas que se configuram a partir da perspectiva das crianças se caracterizam por focalizar as crianças para o estudo das realidades das infâncias. Todavia, importa frisar que esse focalizar não se constitua numa perspectiva de isolamento do sujeito criança, pois “[...] os sujeitos reais somente são inteligíveis vendo-os situados em suas condições biográficas, sociais e culturais concretas: segundo a classe social, a cultura, o gênero, etc. a que pertencem; categorias que, por outro lado se cruzam entre si” (GIMENO SACRISTÁN, 2005, p. 22). Tal procedimento, no nosso entendimento, nos propicia um olhar mais sagaz e menos preconceituoso diante das várias condições concretas de ser criança.

Nessa direção, podemos trazer as indicações de Sarmento e Pinto (1997) que destacam:

[...] o estudo das crianças a partir de si mesmas permite descortinar uma outra realidade social, que é aquela que emerge das interpretações infantis dos respectivos mundos de vida. O olhar das crianças permite revelar fenômenos sociais que o olhar dos adultos deixa na penumbra ou obscurece totalmente (SARMENTO e PINTO, 1997, p. 25). 
Os autores ainda destacam, a necessidade do pesquisador estar atento a não neutralidade de seus olhares, sendo imprescindível exercitar a reflexividade investigativa, pois "[...] constitui um princípio metodológico central para que o investigador adulto não projecte o seu olhar sobre as crianças, colhendo delas apenas aquilo que é o reflexo conjunto de seus próprios preconceitos e representações" (SARMENTO e PINTO, 1997, p. 26). Para considerar o ponto de vista das crianças nas pesquisas, há também a exigência de um certo abandono do olhar centrado no ponto de vista do adulto.

A respeito da discussão objeto e sujeito nas pesquisas, Freitas (2003, p. 29) com base em Rey (1999) traz argumentações esclarecedoras ao se referir ao processo de pesquisa, afirmando que considerar as pessoas investigadas como sujeito "[...] implica compreendê-la como possuidora de uma voz reveladora da capacidade de construir um conhecimento sobre sua realidade que a torna co-participante do processo da pesquisa".

Para contribuir com a construção de um procedimento metodológicos que dê conta dos mundos sociais das crianças e das infâncias, assim como alargar o campo de reflexão teóricometodológica e de pesquisa empírica, Pinto (1997) sugere ser necessário: (i) desconstruir as representações sobre a infância - distinguir a infância como determinada etapa da vida (etária), da infância como conjunto social de características heterogêneas (infâncias); (ii) reconhecer os mundos infantis como dotados de um certo grau de autonomia - é preciso considerar a criança como ativa nos sistemas sociais e que há realidades sociais que só a partir do ponto de vista delas e dos seus universos específicos podem ser analisadas. Nessa perspectiva, consideramos a etnografia como um dos procedimentos privilegiados para a investigação com as crianças.

A utilização da etnografia, como aponta Laplantine (2005, p. 150) “[...] não consiste apenas em coletar, através de um método estritamente indutivo, uma grande quantidade de informações, mas em impregnar-se dos temas obsessionais de uma sociedade, de seus ideais, de suas angústias". Assim, se pretendemos fazer pesquisas nas quais as crianças sejam ouvidas, ou melhor, para que saibamos ouvir e escutar as crianças precisamos nos abrir às suas idéias, aos seus movimentos, às suas ações, às suas angústias, etc.

Temos como exemplo o trabalho de Corsaro (2005), que ao relatar sua experiência etnográfica, na qual estudou as culturas de pares das crianças pequenas em instituições de Educação Infantil, salienta que a etnografia é o método que os antropólogos mais empregam para estudar as culturas exóticas. Ela exige que os pesquisadores entrem e sejam aceitos na vida daqueles que estudam e dela participem. Neste sentido, por assim dizer, a etnografia envolve tornar-se nativo: "Estou convicto de que as crianças têm suas próprias culturas e sempre quis participar delas e documentá-las. Para tanto, precisava entrar na vida cotidiana das crianças - ser uma delas tanto quanto podia" (CORSARO 2005, p. 446).

Para chegar a uma visualização mais aproximada dos modos de vida que constituem as diferentes infâncias em seus contextos sociais, culturais, étnicos, geográficos e históricos, segundo 
Gaitán (2006, p. 245) “[...] se hace preciso, si no inventar métodos, sí adoptar prácticas que permitan analizar de modo específico las variables que conciernen a la misma, y también asumir modos de aproximación a las vidas cotidianas de los niños que conecten con sus propias rutinas e intereses".

Advertidos pelo exposto, é preciso, contudo, o pesquisador estar atento a três esclarecimentos trazidos por Alderson (2005), referente aos direitos das crianças frente ao processo de pesquisa. A primeira é que a participação das crianças envolve uma mudança na ênfase dos métodos e assuntos de pesquisa. Isto quer dizer que, reconhecer as crianças como sujeitos em vez de sujeitados acarreta, na investigação, aceitar que elas podem falar em seu próprio direito e relatar visões e experiências válidas. Uma segunda questão refere-se ao fato de que um dos maiores obstáculos, ao se fazer pesquisas com crianças, é infantilizá-las, percebê-las e tratá-las como imaturas e, com isso, produzir provas que apenas reforçam idéias culturalmente cristalizadas sobre sua incompetência. A terceira questão é o pressuposto, comum aos adultos, de que o consentimento dos pais ou professores basta, e que as crianças não precisam ou não podem exprimir seu próprio consentimento ou recusa a participar de pesquisas.

Sobre essa questão Gaitán (2006, p. 256) destaca que, para além do mero direito de manifestarem recusa em participar das pesquisas, as crianças devem ser informadas sobre todos os aspectos dela antes de dar, ou, não seu consentimento e ser informada “[...] de los objetivos y los métodos elegidos para realizar a investigación, de la forma en que será utilizada y de su finalidad y posibles consecuencias. Sobre esa base libremente deberán consentir (o disentir) de participar en el proceso de investigación".

Deste mesmo fato, Qvortrup (1999, p. 5) levanta importantes apontamentos sobre a interpretação dos dados das ações das crianças, que ele entende não ser possível em razão da criança pertencer a “[...] um grupo etário que não realiza pesquisa [científica e] tem, pois, que deixar a interpretação das suas vidas para outro grupo etário cujos interesses não estão potencialmente em consonância com os seus próprios interesses".

O que, de fato, está contido no cerne desses esclarecimentos não é, senão, três de nossas maiores dificuldades ao realizar pesquisa com crianças, a saber, a lógica adultocêntrica, a entrada no campo e a ética (DELGADO E MÜLLER, 2005).

Sobre a Lógica adultocêntrica as autoras enfatizam ainda que é necessário um interesse pelas crianças, pelos modos como negociam e interagem em grupos, ou seja, $o$ que se passa 'entre' elas, e não 'dentro' delas. É preciso temperar os significados que os adultos tecem sobre as crianças com os significados apontados pelas crianças em linguagens e lógicas distintas daquelas já estabelecidas no mundo adulto.

A entrada no campo, ou seja, a aproximação inicial com as crianças requer novas formas de entrada , como exemplo podemos citar o método de entrada reativa utilizada por Corsaro (2005), que consiste em entrar nas áreas de brinquedo, de relacionamento das crianças e ficar esperando pelas suas reações. 
Quanto à ética, Delgado e Muller (2005) destacam que, em se tratando de pesquisas com crianças, esse é um aspecto fundamental, pois é inegável que existe uma força adulta baseada no tamanho físico, nas relações de poder e nas decisões, no mais das vezes, unilaterais. A esse respeito Kramer (2002) destaca três pontos a serem observados. O primeiro é com relação aos nomes das crianças observadas ou entrevistadas devem ser verdadeiros ou fictícios? Devem ou não ser explicitados na apresentação da pesquisa? A segunda questão refere-se a utilização de imagens de crianças, sejam elas de fotografias, vídeos ou filmes. A terceira questão ética refere-se às implicações e impactos sociais dos resultados de trabalhos científicos.

Temos como exemplo a pesquisa de Simão (2007), que analisou 18 dissertações desenvolvidas em diferentes áreas do conhecimento no campo científico e que tratavam de corpo, infância e educação. A autora destaca que 11 das dissertações analisadas caracterizaram-se como pesquisas empíricas: três estudos de caso, uma pesquisa etnográfica, uma análise de discurso de pediatras, uma investigação das práticas narrativas de um menino de 9 anos e cinco pesquisas de abordagem qualitativa envolvendo crianças e profissionais da creche.

Essas 11 dissertações utilizaram como procedimento de recolha de informações das crianças e profissionais, a observação, a entrevista, a produção de vídeo, a gravação em fita cassete, jogos e brincadeiras, histórias, ilustrações, fotografias e desenhos, dinâmica com cartões, atividades de educação motora, passeios pela cidade e atividades com maquetes. Não houve, no entanto, referências a consentimentos das crianças para participação nas pesquisas, tal como delineado por autores citados acima. Este é um indicativo de que ainda se tem pouco cuidado com a subjetividade e privacidade das crianças nas pesquisas que envolvem aspectos da vida delas.

Não há dúvidas de que já não velejamos à deriva em busca de novas possibilidades metodológicas que permitam vislumbrar a inclusão das crianças nos processos de pesquisas. Muito claro já está a necessidade de deslocarmos da ênfase perpetuada nas pesquisas sobre as crianças para concretizarmos pesquisas com as crianças.

A pergunta que agora emerge é: como, verdadeiramente, permitir que as crianças participem no processo de pesquisa a partir de seus reais interesses? Como ler os interesses das crianças se a sua comunicação não se esclarece com base na sua capacidade de argumento verbal?

Esclarecer essa questão não é tarefa fácil, bem sabemos, tampouco se é possível esclarecer! Não bastasse a dificuldade, temos ainda que considerar que essas são condições justapostas, em cuja articulação reside novas exigências teórico-metodológicas, não mais única, tendenciosa, dogmática; mas articulada, complexa, aberta, processual e participativa. Apesar de valorizarmos as contribuições trazidas por vários campos teórico-metodológicos - Sociologia, Antropologia, Fenomenologia, Psicologia etc. -, não é mais possível, pois, tratar de e com as crianças limitando-nos a apenas um desses campos. 
A rigor, não podemos mais nos recusar ao esforço de produzir pesquisas valendo-nos de cruzamentos teóricos multidisciplinares e não somente isso. Se pretendemos ser coerentes frente a nossa tarefa de investigar, compreender e participar das complexidades que constituem o fenômeno das infâncias e das crianças, temos que verdadeiramente estar empenhados em estabelecer uma relação horizontal com os saberes que as crianças produzem em sua especificidade de ser gente nova.

\section{A Educação Física e sua possibilidade de contribuição metodológica}

Saffioti (1998), criativamente, define uma possibilidade dinâmica de pesquisa através de cruzamentos metodológicos como nó: “O nó não apresenta a frouxidão dos laços que se desfazem ao menor movimento. Tampouco é duro a ponto de se tornar irreconhecíveis as contradições que o compõem. E, sobretudo, deixa as pontas dos eixos à vista, dispostas a revelar suas especificidades" (SAFFIOTI, 1998, p. 9). Ou seja, para a autora, essa possibilidade metodológica não significa a obrigação de trilhá-la sobre nós apertados, mas a possibilidade de entrever e deslizar em um fenômeno permeado por inúmeros outros aspectos.

Colocar em prática esse procedimento, sem, contudo, incorrer em superficialidade ou relativismo metodológico, é tarefa árdua, visto que não exige apenas fôlego para estabelecer confrontos multidisciplinares, mas, também, e sobretudo, rigor metodológico originado em pressupostos filosóficos.

Como destaca Santos (2008, p. 107) uma ecologia de saberes não implica a aceitação do relativismo: "Pelo contrário, na perspectiva de uma pragmática da emancipação social, o relativismo, enquanto ausência de critérios de hierarquia entre saberes, é uma posição insustentável pois, torna impossível qualquer relação entre conhecimento e o sentido de transformação social". Ou seja, se tudo tem igual valor, todos os projetos de transformação social podem ser igualmente válidos, ou inválidos! Por isso a ecologia de saberes visa criar uma nova forma de relacionamento entre o conhecimento científico e outras formas de conhecimento, concedendo igualdade de oportunidades às diferentes formas de saber envolvidas em disputas epistemológicas cada vez mais amplas, o que não indica atribuir igual valor a todos os tipos de saberes, mas indica não desqualificar $a$ priori tudo que não se ajuste ao cânone epistemológico da ciência moderna.

A especificidade da Educação Física como área que trata do tema da linguagem, nos coloca essa prova: linguagem do movimento, linguagem corporal, gestualidades. Eis o limite de um enfoque exclusivamente lingüístico e a exigência de uma amplitude filosófica. 
Outro aspecto que devemos destacar diante dessa exigência refere-se ao recorrente questionamento feito, em especial pelo campo da Sociologia da Infância, acerca do modo de ser criança. Se a categoria da infầncia e as próprias crianças possuem uma especificidade, quais são elas e o que marca o seu tempo específico? Como realizar pesquisa de modo coerente com a especificidade das crianças na Educação Física dispensando vez e voz a elas e, ao mesmo tempo, levar em conta que o olhar específico desse campo não se detém, unicamente, à capacidade de argumentos verbais das crianças?

A questão maior que subjaz todas essas outras é, justamente, o da linguagem, tema este tão pouco aprofundado para a categoria da infância, e, principalmente, no campo da Educação Física infantil. Dentre os autores que já dedicaram esforços em compreender esse tema na Educação Física, podemos citar os trabalhos de Kunz (2001 e 2004), Araújo (2005) e Gomes-da-Silva (2007).

A problemática da necessidade de instrumentos de pesquisa que possibilitem captar as diferentes linguagens expressivas das crianças, ainda é crucial na esfera da infância e da Educação infantil. Rocha (2005) já denunciou que a problemática maior ao se fazer pesquisas com crianças está na necessidade de atentar às diferentes linguagens e aos limites no grau de compreensão que se pode atingir:

[...] e lembremos que, quando o outro é uma criança, a linguagem oral não é central e nem única, ela é fortemente acompanhada de outras expressões corporais, gestuais e faciais. Isso já nos indica alguns dos problemas metodológicos envolvidos na pesquisa com crianças (ROCHA, 2005, p. 3).

O desenvolvimento de estratégias que possibilitem a leitura da linguagem corporal, da linguagem do movimento, seria uma perspectiva de conhecer melhor as crianças. A pergunta que nos fazemos é: em que medida a Educação Física com seu enfoque específico tem contribuído para ampliar, ou aperfeiçoar, as pesquisas com crianças no âmbito da Educação Infantil, diante das problemáticas e dificuldades que surgem incessantemente no processo investigativo? O que estamos percebendo é que, a maioria das dificuldades, até aqui, apontadas como limites para a realização de uma pesquisa participativa e coerente, são questões/temáticas caras à Educação Física, especialmente o tema da linguagem específica da criança, isto é, o movimento "livre" e autônomo no sentido de ser relativo ao sentido e significado atribuído pela própria criança à sua ação (Kunz, 2004).

Ora, se partirmos do pressuposto de que para trabalhar com crianças é preciso conhecer as crianças, então precisamos conhecer melhor sobre a sua linguagem, o que implica a necessidade de 
adentrar ao tema do movimento expressivo - Se-Movimentar ${ }^{3}$ - e da linguagem corporal. Só assim, poderemos compreender como as crianças se comunicam, ou seja, apresentam seu ponto de vista.

Além disso, são também temáticas próprias da Educação Física as que são trazidas por Sarmento (2004) como os eixos que estruturam as culturas infantis, a saber, interatividade (as crianças estão nas relações, com seus pares, com outras gerações e com o mundo que as rodeia), ludicidade (as crianças brincam, mas seriamente...), fantasia do real (capacidade que a criança tem em articular fantasia com realidade, transformar real em fantasia e fantasia em realidade), e reiteração (necessidade que a criança tem de vivenciar mais de uma vez uma experiência; ela repete inúmeras vezes, mas nunca é a mesma coisa; a cada ação, o sentido que atribui é outro em relação à ação anterior).

O curioso é que, algumas vezes, ouvimos discursos - baseados em fatos, é verdade - de que a Educação Física sofre crise de identidade acadêmica e educativa, ao passo que o que nos evidencia, pelo menos na esfera infantil, é que à especificidade da Educação Física pertence a fonte capaz de prover novas possibilidades metodológicas e investigativas com crianças, visto que pode nos auxiliar a compreender o que é e como é ser criança: corpo e movimento expressivo.

Assumir que a criança é corporificada no movimento expressivo - sua linguagem, seu modo de ser - nos leva ao encontro delas próprias, exatamente o que sugerem os campos da Sociología da Infância, da Antropologia da Criança e da Fenomenologia. Assim, o que se espera, é que abandonemos nossas concepções puramente adultocentradas a respeito das crianças e passemos a dialogar com elas nas pesquisas e não apenas sobre elas, de tal sorte que, se quisermos incluí-las, há de ser também através de características marcantes do fazer delas, como: brincar, jogar, enfim SeMovimentar, que a sua vez, é característica marcante das preocupações teóricas e práticas no campo da Educação Física.

É relevante destacar que, embora atualmente muitos procedimentos etnográficos tenham se realizado com as crianças em busca de compreender a experiência da infância a partir delas próprias, ainda temos o desafio da definição de metodologias de pesquisas que se aproximem mais dos processos pelos quais as crianças brincam, se divertem, sofrem, interagem, desenvolvem sua identidade e seus relacionamentos por meio da dimensão corporal.

\footnotetext{
${ }^{3}$ Kunz $(2001,2004)$, baseado nos trabalhos dos holandeses Gordijn e Tamboer e, principalmente, do alemão A. Trebels, tem defendido o movimento humano a partir de sua inerente potencialidade dialógica, em cujo fundamento está a possibilidade da compreensão de temas como sensibilidade, percepção e intuição humana. Dessa concepção surge a expressão Se-Movimentar, na qual o Se, como Kunz escolheu traduzir a expressão alemã Sich-bewegen, refere-se à próprio, ou seja, ao sujeito do movimento. Com base na abordagem fenomenológica do movimento humano, entendese que o substrato capaz de articular e significar as várias outras linguagens é, exatamente, o movimento, aqui entendido como movimento expressivo - aquele que conta a história de cada sujeito, diz quem ele é.
} 
Gaitán (2006, p. 254) indica, como possível desafio metodológico o juego de rol, quer dizer, o jogo de faz de conta ou jogo de papéis, no qual as crianças desempenham papéis, com personalidade que normalmente não é real. A autora sublinha que esse tipo de jogo se torna útil para observar a linguagem corporal das crianças: "En las fases iniciales de la investigación, el juego de rol puede resultar útil para averiguar cosas sobre las palabras y conceptos empleados por los niños, así como observar el lenguaje corporal y las costumbres".

Vale acrescentar, que não estamos, de maneira alguma, tentando afirmar que as temáticas fundamentais da categoria da infância estão sobre os domínios prioritários do campo da Educação Física. Tal atitude não seria coerente com conduta que defendemos para o processo de pesquisa com crianças: cruzamentos teórico-metodológicos e multidisciplinares. O que pretendemos, é chamar atenção do campo da Educação Física Infantil para a possibilidade que temos de ampliar a nossa participação junto às pesquisas que primam por incluir as crianças como partícipes da e na produção do conhecimento.

\section{Considerações Finais}

Com base nos apontamentos teóricos levantados nesse artigo, o que concluímos é que não é mais possível realizar pesquisas com crianças sem considerar as especificidades, os modos próprios de ser criança, de tal sorte que, o nosso dever maior é não nos eximir da necessidade de articulações teórico-metodológicos no processo de pesquisa, como já anunciamos.

Não basta, pois, nos valermos, nas pesquisas, de uma única matriz interpretativa e ainda respaldada apenas no nosso próprio repertório para cumprir essa tarefa. As crianças possuem representações diferentes das nossas, vivem em tempos e gerações diferentes dos nossos, possuem modos (linguagens) diferentes dos nossos de experienciar a vida e, portanto, também representam de modos diferentes. Isto quer dizer que precisamos nos permitir percebê-las na dimensão delas mesmas e não a partir das representações que temos sobre elas, isso implica desconstruir as imagens/concepções que temos já cristalizadas acerca das crianças.

Caso assim procedamos, no processo de pesquisa, abertos e isentos de pré-conceitos sobre as crianças, talvez seja viável manter viva esperança de iluminação para novas possibilidades de pesquisar, de novos aportes teórico-metodológicos, enfim, de novos olhares, capaz de nos mostrar novos mundos, mais sensível talvez.

Para nós, ainda vale a pena continuar alimentando a esperança de um dia ver nascer novas instituições, novas práticas pedagógicas/novos processos educativos, não mais injusta, coercitiva e incoerente com o modo de ser criança, mas, efetiva, prazerosa e significativa para ela, sem com isso 
negar a preocupação em relação à apropriação do patrimônio de conhecimentos sistematicamente acumulados pela humanidade (direito legítimo de todas as crianças). Outrossim, este é um processo comunicativo, onde às crianças é dispensado vez e possibilidades expressivas, portanto, não é mais uma idealização institucional para elas, mas uma produção juntos com elas.

Com a afirmação de possibilidades expressivas, queremos enfatizar que a maior possibilidade expressiva das crianças não reside apenas na capacidade de articulação do argumento verbal, mas na capacidade de articular várias linguagens indissociavelmente.

Provavelmente, as crianças sabem bem mais sobre os adultos, sobre seus corpos, seus movimentos e também sobre as instituições do que somos capazes de perceber, pois ainda conhecemos pouco sobre suas idéias a partir delas mesmas, sobre o que elas pensam dos adultos, dos seus corpos e de seus movimentos e sobre as escolas que criamos pensando nelas e nas suas necessidades. Talvez as crianças possam nos ajudar a perceber o que já não conseguimos enxergar pela lente de uma lógica monocultural e imperial. Talvez devêssemos começar por descobrir com elas onde está a chave capaz de religar o motor da sensibilidade que parece apartado das relações humanas.

Ainda temos um longo caminho a percorrer no processo de pesquisa para e com as crianças, suas experiências e culturas, a fim de que se torne mais coerente com elas, já que são sujeitos interessadamente partícipes do processo. À Educação Física parece-nos caber uma parte significativa de responsabilidade contributiva, da qual não é mais possível recuar, como temos feito, há muito tempo, ao delimitar o nosso olhar.

\section{Investigación con niños en la Educación Física: cuestiones teóricas y desafíos metodológicos}

\section{Resumen:}

El presente ensayo busca ampliar subsidios que permitan una comprensión del punto de vista de los niños en la dimensión de la investigación en Educación Física Infantil. Se trata de una reflexión teórica, en la cual la revisión de la literatura permitió delimitar los parámetros del abordaje del tema y proponer su problematización. La conclusión apunta para la necesidad de adoptarse, en las investigaciones con niños, un abordaje multidisciplinar como aporte metodológico, que posibilite, de hecho, percibirlas e incluirlas como partícipes de la misma y en la producción de conocimientos, especialmente aquellas que las afectan directamente y que pueden proyectar nuevas formas de intervención educativa.

Palabras-clave: investigación, infancia, educación física, educación infantil. 


\title{
Research with children Fhysical Education: theoretical issues and methodological challenges
}

\begin{abstract}
:
This essay aims extend subsidies to enable an understanding of the views of children in the size of the search in Children's Physical Education. This is a theoretical reflection, in which the review of the literature has set the parameters of the approach of the issue and propose their problematization. The conclusion points to need to adopt, in research with children, a multidisciplinary approach as a contribution methodology enabling, in fact, understand and include them as participants and in the production of knowledge, especially those that directly affect and can focusing new forms of educational intervention.
\end{abstract}

Keywords: research, childhood, physical education, childhood education.

\section{Referências Bibliográficas}

ALDERSON, Priscilla. As crianças como pesquisadoras: os efeitos dos direitos de participação sobre a metodologia de pesquisa. Revista Educação e Sociedade. Campinas, v.26, n.91, p. 419-442, maio/ago, 2005.

ARAÚJO, Lisia. C. G de. Linguagem, intersubjetividade e movimento humano. Dissertação (Mestrado em Educação Física) - Centro de Desportos, Universidade Federal de Santa Catarina, Florianópolis, 2005.

ARIÈS, Philippe. História Social da Criança e da Família. Rio de Janeiro: LTC, 1981.

CORSARO, William A. Entrada no campo, aceitação e natureza da participação nos estudos etnográficos com crianças pequenas. Revista Educação e Sociedade. Campinas, v.26, n.91, p. 443-464, maio/ago, 2005.

DELGADO, Ana Cristina Coll ; MÜLLER, Fernanda. Apresentação - Sociologia da Infância: pesquisa com crianças. Revista Educação e Sociedade. Campinas, v.26, n.91, p. 351-360, maio/ago, 2005.

FREITAS, Maria Tereza. A perspectiva sócio-histórica: uma visão humana da construção do conhecimento. In: FREITAS, Maria Teresa; SOUZA, Solange Jobin ; KRAMER, Sônia (org.) Ciências humanas e pesquisa: leituras de Mikhail Bakhtin. São Paulo: Ed. Cortez, 2003.

GAITÁN, Lourdes. Sociología de la infância: análisis e intervención social. Editora Sintesis, Madrid, 2006.

GIMENO SACRISTÁN, José. O aluno como invenção. Porto Alegre: Artmed, 2005.

GOBBI, Márcia. Lápis vermelho é coisa de mulherzinha: desenho infantil, relações de gênero e educação infantil. 1997. Dissertação (Mestrado em Educação). Universidade de Campinas. Campinas, SP, 1997.

GOMES-DA-SILVA, Eliane. Educação (física) infantil: se-movimentar e significação. 2007. Dissertação (Mestrado em Educação Física) - Centro de Desportos, Universidade Federal de Santa Catarina, Florianópolis, 2007. 
ITURRA, Raul. A epistemologia da infância: ensaio de antropologia da educação Educação Sociedade e Culturas. n.17, p.135-153, 2002.

JAMES, Allison ; JENKS Chris ; PROUT, Alan. O corpo e a infância. In: KOHAN, Walter Omar; KENNEDY, David. Filosofia e infância: possibilidades de um encontro., $2^{\text {a }}$ Ed. Petrópolis: Ed. Vozes, p. 207-238, 2000.

KUHLMANN JR, Moisés. Infância e Educação Infantil: uma abordagem histórica. Porto Alegre: Mediação, $2^{\mathrm{a}}$ Edição. 210p. 2001.

KUNZ, Elenor. Transformação didático-pedagógica do esporte. 4. ed. Ijuí: Editora Unijuí, 2001.

KUNZ, Elenor. Práticas didáticas para um "conhecimento de si" de crianças e jovens na educação física. In: (Org.). Didática da educação física 2. ed. Ijuí: Editota Unijui, . p. 15-52, 2004.

KRAMER, Sônia. Autoria e autorização: questões éticas na pesquisa com crianças. Cadernos de Pesquisa. São Paulo:Autores Associados. n. 116, p. 41-59, jul. 2002.

LAPLANTINE, François. Aprender antropologia. São Paulo: Brasiliense, 2005.

NUNES, Ângela. A criança na Antropologia: apreciações bibliográficas iniciais. In: $A$ sociedade das crianças A’uwe-Xavante. Lisboa: Instituto da Inovação Educacional, Ministério da Educação, 1999.

PINTO Manuel. A infância como construção social. In: As crianças e a infância: definição As crianças: Contextos e Identidades. Braga, Portugal: Centro de Estudos da Criança, Universidade do Minho, 1997.

PROUT, Alan. Reconsiderar a Nova Sociologia da Infância: para um estudo interdisciplinar das crianças. Ciclo de conferências em Sociologia da Infância 2003/2004. Departamento de Ciências Sociais Aplicadas. Universidade de Stirling, 23 pág. 2004. Disponível no endereço:

http:/www.iec.uminho.pt/ModuleLeft.aspx?mdl= /Modules/UMEventos/EventoView.ascx\&ItemID=128\&Mi $\mathrm{d}=37 \&$ lang=pt-T\&pageid=25\&tabid=11. Acessado em 03 de março de 2005.

QVORTRUP, Jens. A infância na Europa: novo campo de pesquisa social. Minho: CEDIC, Instituto de estudos da criança, Universidade do Minho, (mimeo), 1999.

ROBERTS, Helen. Ouvindo as crianças: e escutando-as. In: CHRISTENSEN, Pia e JAMES, Allison. Investigação com Crianças: perspectivas e práticas. Porto, p. 243-260, 2005.

ROCHA, Eloisa Acires Candal. Por que ouvir as crianças? Algumas questões para um debate científico multudisciplinar. (mimeo), 2005.

SAFFIOTI, Heleieth I. B. Prefácio. In: SILVA, Maria Aparecida de Moraes. Errantes do fim do século. São Paulo: Editora da Unesp, 1999. p. 5-9.

SANTOS, Boaventura de Souza. A gramática do tempo: para uma nova cultura política. $2^{\mathrm{a}}$ edição. São Paulo: Cortez, 2008.

SARMENTO, Manuel Jacinto ; PINTO, Manuel. As crianças: Contextos e Identidades. Braga, Portugal: Centro de Estudos da Criança, Universidade do Minho, 1997. 
SARMENTO, Manuel Jacinto. As culturas da infância nas encruzilhadas da segunda modernidade. In: Crianças e Miúdos: Perspectivas sócio-pedagógicas da infância e educação. Coleção em foco, Edições Asa, Portugal, p. 09-34, 2004.

SARMENTO, Manuel Jacinto. Crianças: educação, culturas, cidadania activa, refletindo em torno de uma proposta de trabalho. Perspectiva: Revista do Centro de Ciências da Educação. Florianópolis $v$ 23, p. 1739, jan/jul, 2005.

SIROTA Regine. Emergência de uma sociologia da infância: evolução do objeto e do olhar. Cadernos de Pesquisa. n. 112, p. 7-31. março/ 2001.

SILVA, Mauríco Roberto. da. Trama doce-amarga: exploração do trabalho infantil e cultura lúdica. São Paulo: Hucitec, Editora da Unijuí, 2003.

SIMÃO, Márcia Buss. Infância, corpo e educação na produção científica brasileira (1997-2003). 2007. 224 p. Dissertação (mestrado), PPGE/UFSC, Universidade Federal de Santa Catarina, Florianópolis, 2007.

TOMÁS, Catarina ; SOARES, Natália Fernandes. Infância, protagonismo e cidadania: contributos para uma análise sociológica da cidadania da infância. Fórum sociológico. $n^{\circ}$ 11/12 ( $2^{\mathrm{a}}$ série), p. 349-361, 2004. 